\title{
A Survey of Factors Influencing Drug Choice and the Prescribing Attitudes Among Junior Doctors of Two Major Tertiary Care Hospitals in Chittagong City
}

\author{
Jannatul Ferdoush ${ }^{1 *}$ \\ Abhijit Chowdhury ${ }^{2}$ \\ Kohinoor Parveen ${ }^{3}$ \\ Maliha $\mathrm{Ata}^{4}$ \\ Sefa Sarwath Alam ${ }^{5}$ \\ Fahim Hassan Reza ${ }^{6}$
}

'Department of Pharmacology \& Therapeutics BGC Trust Medical College, Chittagong, Bangladesh.

${ }^{2} \mathrm{PhD}$ Research Fellow

Centre for Clinical Epidemiology and Biostatistics Hunter Medical Research Institute,

The University of Newcastle Australia.

${ }^{3}$ Department of Pharmacology \& Therapeutics Rangamati Medical College, Rangamati, Bangladesh.

${ }^{4}$ Department of Pharmacology \& Therapeutics Chattagram Maa-O-Shishu Hospital Medical College Chittagong, Bangladesh.

${ }^{5}$ Department of Pharmacology \& Therapeutics Cox's Bazar Medical College

Cox's Bazar, Bangladesh.

${ }^{6}$ Department of Pediatrics Chattagram Maa-O-Shishu Hospital Medical College Chittagong, Bangladesh.

\section{${ }^{*}$ Correspondence to:}

\section{Dr. Jannatul Ferdoush}

Associate Professor

Department of Pharmacology \& Therapeutics BGC Trust Medical College

Chittagong, Bangladesh

Mobile : +88 01856189977

Email: jannat_fkh@yahoo.com

www.banglajol.info/index.php/CMOSHMCJ

\begin{abstract}
Background: The magnitude of rational prescribing is well known but the irrationalities and errors in prescriptions are seen worldwide as the training of future doctors is still not up to the mark. This study aimed to find out the factors influencing drug choice and the prescribing attitudes among junior doctors of two major tertiary care hospitals in Chittagong city. Methods: A cross-sectional questionnaire survey was conducted among the junior doctors of Chittagong Medical College Hospital $(\mathrm{CMCH})$ and Chattagram Maa -O- Shishu Hospital Medical College (CMOSHMC) to assess the factors influencing drug choice and the prescribing attitudes among junior doctors during August 2016. Results: The questionnaires were provided to 220 participants of whom $162(73.63 \%)$ participants provided a complete response to the survey. The response rate was $75.89 \%$ in $\mathrm{CMOSHMCH}$ and $71.29 \%$ in $\mathrm{CMCH}$. The majority $(87.03 \%)$ of junior doctors mentioned that they are highly influenced by their supervising senior doctors' patterns of prescriptions. About $79.01 \%$ of them took the cost of drugs into consideration while prescribing. $58.64 \%$ of the prescribers reported their confidence while prescribing without supervision. On the otherhand, $33.33 \%$ doctors mentioned that side effects of the drug changed their patterns of prescriptions. Only one-third (33.95\%) of the junior doctors opined that the pharmaceutical promotional offers never influence them. Conclusion: Junior doctors decide their drug of choice mainly by copying their supervising senior doctors' prescriptions without knowing how to choose, and they feel less confident while prescribing. Issues of drug cost, adverse drug reactions concerned the majority of the participants, but they do not have the clear ideas on how to deal with these practice behaviours. Moreover, pharmaceutical promotional offers significantly persuaded the junior doctors' prescription patterns. So, there is a need for the continuous medical education programs in hospital settings to train the junior doctors for building capacities and competencies while prescribing.
\end{abstract}

Key words: Prescription; Drug Choice; Junior Doctors; Medical Education.

\section{INTRODUCTION}

Irrational, inappropriate, or sometimes even harmful prescribing behaviour among junior doctors is a growing concern in the present day's health sector ${ }^{1}$. This group of physicians has the scarcity of knowledge on therapeutic reasoning unlike the critical diagnostic thinking ${ }^{2,3}$. Little is known about how this group of clinicians should make the choice of prescription for a particular a drug/drugs ${ }^{2}$. Knowledge regarding the rational prescribing of a drug/drugs is considered as a 'matter of knowing' which evolves over time by following senior fellow physicians and surgeons rather than following an evidence-based approach ${ }^{4}$. Senior doctors often follow a 'mental standard treatment guideline' while prescribing for common ailments ${ }^{4,5}$. Very often senior doctors are persuaded by their preoccupied mind to make the choice of a certain treatment strategy rather than following a standard international guideline ${ }^{6}$. 
There is also a deficiency in training up the junior doctors regarding a standard prescribing behaviour making many graduates under-prepared and less confident even after the gradua$\operatorname{tion}^{7}$. Numerous research is trying to understand the factors affecting the prescribing attitude among junior doctors regarding decision making and critical pharmacological reasoning during practice $^{8,9}$. The undergraduate and postgraduate education, various social factors, the influence of the supervising senior doctor, etc. are among these potential factors ${ }^{10-13}$.

As the majority of prescriptions in tertiary care hospitals in Bangladesh are done by junior doctors, there is a grave importance of a proper assessment regarding the prescribing attitudes among this fraternity of practising physicians. Taking that into account, we carried out this survey with the aim to investigate the factors impacting the choice of drugs and the prescribing attitudes of junior doctors in Chittagong Medical College Hospital $(\mathrm{CMCH})$ and Chattagram Maa -O- Shishu Hospital Medical College (CMOSHMC) the two largest government and private tertiary care hospitals respectively in Chittagong city of Bangladesh.In the perspective of Bangladesh, junior doctors include the interns, indoor medical officers, assistant registrars, post-graduate trainees like residents and honorary medical officers. On the other hand, senior doctors cover registrars, house physicians and surgeons, assistant to full professors. To the authors' knowledge, no study of this kind has been attempted so far in medical college hospital setting in Bangladesh.

\section{MATERIALS AND METHODS}

For this study, a cross-sectional questionnaire survey among the junior doctors of $\mathrm{CMCH}$ and CMOSHMC to evaluate the factors influencing drug choice and the prescribing attitudes during July 2016 was carried out. All the completed questionnaires were collected and assessed properly by the Department of Pharmacology \& Therapeutics of the respective medical colleges.

\section{RESULTS}

\section{Demographic Characteristics}

220 junior doctors participated in the study of which 162 (73.64\%) participants completed the survey. The response rate was $75.89 \%$ in CMOSHMC and $71.29 \%$ in CMCH. In CMOSHMC 80\% were male, and $20 \%$ were female while in $\mathrm{CMCH}$ the percentages were $70 \%$ and $30 \%$, respectively (Table 1 ).

Table 1: Demographic characteristics

\begin{tabular}{|c|c|c|c|}
\hline & $\begin{array}{c}\text { All } \\
73.63 \% \\
n=162 / 220\end{array}$ & $\begin{array}{c}\text { CMOSHMC } \\
\mathbf{7 5 . 8 9 \%} \\
\mathbf{n}=85 / 112\end{array}$ & $\begin{array}{c}\text { CMCH } \\
71.29 \% \\
\mathrm{n}=77 / 108\end{array}$ \\
\hline \multicolumn{4}{|l|}{ Sex } \\
\hline \multirow[t]{2}{*}{ Male } & $75.30 \%$ & $80 \%$ & $70.12 \%$ \\
\hline & $122 / 162$ & $(68 / 85)$ & $(54 / 77)$ \\
\hline \multirow[t]{2}{*}{ Female } & $24.69 \%$ & $20 \%$ & $29.87 \%$ \\
\hline & $40 / 162$ & $17 / 85$ & $23 / 77$ \\
\hline
\end{tabular}

\section{Factors Influencing Drug Selection}

As indicated in Table 2, 84.56\% junior doctors think that their supervising senior physicians and surgeons are cooperative towards their independent prescribing attitude. $87.03 \%$ of the junior doctors mentioned that they are highly affected by their supervising physicians' patterns of prescriptions. Only $4.32 \%$ junior physician shave little influence while prescribing. Almost half of the junior doctor (55.69\%) follows senior doctors' prescriptions. About $79.01 \%$ of junior doctors take the cost of drugs into serious consideration during their practice. The cost of the drug is not at all critical to $5.55 \%$ of junior doctors.

Table 2 : Factors influencing drug selection, rated by junior doctor

$\begin{array}{cccc}\text { Factors } & \text { All } & \text { CMOSHMC } & \text { CMCH } \\ & 73.63 \% & 75.89 \% & 71.29 \% \\ \mathrm{n}=162 / 220 & \mathrm{n}=85 / 112 & \mathrm{n}=\mathbf{7 7 / 1 0 8}\end{array}$

To what extent you find your supervising senior doctors cooperative towards your independent prescription of drugs?

$\begin{array}{llll}\text { Cooperative } & 84.56 \% & 84.70 \% & 85.54 \%\end{array}$

$\begin{array}{lrrr} & 137 / 162 & 72 / 85 & 65 / 77 \\ \text { Less cooperative } & 10.49 \% & 9.41 \% & 11.28 \% \\ & 17 / 162 & 8 / 85 & 9 / 77 \\ \text { Not cooperative } & 4.93 \% & 5.88 \% & 3.18 \% \\ & 8 / 162 & 5 / 85 & 3 / 77\end{array}$

To what degree do your supervising senior doctors' patterns of prescriptions influence you?

$\begin{array}{lrrr}\text { High } & 87.03 \% & 87.05 \% & 87.20 \% \\ \text { Low } & 141 / 162 & 74 / 85 & 67 / 77 \\ & 8.64 \% & 9.41 \% & 7.23 \% \\ \text { Very low } & 14 / 162 & 8 / 55 & 6 / 77 \\ & 4.32 \% & 3.52 \% & 5.57 \% \\ & 7 / 162 & 3 / 85 & 4 / 77\end{array}$

To what percentage youexactly follow your supervising senior doctors' patterns of prescriptions?

$\begin{array}{lrrr}80-100 \% & 38.27 \% & 37.64 \% & 39.19 \% \\ 50-80 \% & 62 / 162 & 32 / 85 & 30 / 77 \\ & 65.69 \% & 48.23 \% & 51.67 \% \\ <50 \% & 81 / 162 & 41 / 85 & 40 / 77 \\ & 16.32 \% & 14.11 \% & 9.11 \% \\ & 19 / 162 & 12 / 85 & 7 / 77\end{array}$

To what degreeyou believe you are influenced by the promotional offers of pharmaceutical companies before prescribing a drug/drugs?

$\begin{array}{llll}\text { Never } & 33.95 \% & 37.64 \% & 29.12 \%\end{array}$

$\begin{array}{lll}55 / 162 & 32 / 85 & 23 / 77\end{array}$

$\begin{array}{lrr}\text { A little } \quad 46.91 \% & 45.88 \% & 49.88 \%\end{array}$

$\begin{array}{rrr}76 / 162 & 39 / 85 & 37 / 77\end{array}$

High $\quad 19.13 \% \quad 16.46 \% \quad 21.96 \%$

$31 / 162 \quad 14 / 85 \quad 17 / 77$

How important is the cost of thedrug in your prescription?

$\begin{array}{llll}\text { Important } & 79.01 \% & 81.17 \% & 76.35 \%\end{array}$

$\begin{array}{rrr}128 / 162 & 69 / 85 & 59 / 77\end{array}$

Not very important $\quad 15.43 \% \quad 14.11 \% \quad 16.67 \%$

$\begin{array}{lll}25 / 162 & 12 / 85 & 13 / 77\end{array}$

Not at all importance $\quad 5.55 \% \% \quad 4.70 \% \quad 6.98 \%$

$9 / 162 \quad 4 / 85 \quad 5 / 77$




\section{The Prescribing Attitudes of Junior Doctors}

Table 3 presents the information regarding the prescribing attitudes among junior doctors. $58.64 \%$ of the junior prescribers feel that they are confident while prescribing a drug/drugs without the supervision of the senior doctors while only $14.81 \%$ the junior doctors feel that they are less confident without proper supervision. Before prescribing a drug/drugs, only $45.58 \%$ junior doctors check the current guidelines. In the questions regarding taking proper drug history of the patient, almost half of the doctors do not take a proper drug history during admission/OPD consultation. Only $41.35 \%$ physicians check interactions before prescribing multiple drugs at a time.

Table 3 : Prescribing attitudes of junior doctors

$\begin{array}{cccc}\text { Factors } & \text { All } & \text { CMOSHMC } & \text { CMCH } \\ & \mathbf{7 3 . 6 3 \%} & \mathbf{7 5 . 8 9} \% & \mathbf{7 1 . 2 9} \% \\ \mathrm{n}=162 / 220 & \mathrm{n}=\mathbf{8 5} / 112 & \mathrm{n}=\mathbf{7 7 / 1 0 8}\end{array}$

To what extent you feel confident while prescribing drugs without supervision?

$\begin{array}{lrrr}\text { Very confident } & 25.92 \% & 21.17 \% & 32.25 \% \\ & 42 / 162 & 18 / 85 & 24 / 77 \\ \text { Confident } & 58.64 \% & 56.47 \% & 61.45 \% \\ & 48 / 162 & 48 / 85 & 47 / 77 \\ \text { Less confident } & 14.81 & 22.34 \% & 6.98 \% \\ & 24 / 162 & 19 / 85 & 5 / 77\end{array}$

To what extent you check the current guidelines before prescribing drug/drugs?

$\begin{array}{lrrr}\text { Always } & 45.58 \% & 37.64 \% & 28.76 \% \\ \text { When feeling necessary } & 54 / 162 & 32 / 85 & 22 / 77 \\ & 33.95 \% & 58.82 \% & 66.35 \% \\ \text { Never } & 55 / 162 & 50 / 85 & 5 / 77 \\ & 4.32 \% & 3.52 \% & 4.88 \% \\ & 7 / 162 & 3 / 85 & 4 / 77\end{array}$

To what extent you review the current literature regarding different drugs in your daily clinical practice?

$\begin{array}{lrrr}\text { Always } & 22.83 \% & 42.35 \% & 40.14 \% \\ \text { When feeling necessary } & 37 / 162 & 36 / 85 & 31 / 77 \\ & 77.53 \% & 47.05 \% & 48.72 \% \\ \text { Never } & 11.11 \% & 40 / 85 & 37 / 77 \\ & 18 / 162 & 10.58 \% & 11.16 \% \\ & 9 / 85 & 9 / 77\end{array}$

To what extent you check for the drug interactions before prescribing multiple drugs at a time?

$\begin{array}{lrrr}\text { Always } & 41.35 \% & 45.88 \% & 36.47 \% \\ \text { When feeling necessary } & 67 / 162 & 39 / 85 & 28 / 77 \\ & 51.85 \% & 44.69 \% & 57.94 \% \\ \text { Never } & 84 / 162 & 39 / 85 & 45 / 77 \\ & 7.4 \% & 8.23 \% & 5.59 \% \\ & 12 / 162 & 8 / 85 & 4 / 77\end{array}$

To what extent you take proper drug history from the patients during admissions/OPD consultations?

$\begin{array}{lrrr}\text { Always } & 44.44 \% & 50.58 \% & 36.24 \% \\ & 72 / 162 & 44 / 85 & 28 / 77 \\ \text { When feeling necessary } & 42.59 \% & 37.63 \% & 48.56 \% \\ & 69 / 162 & 32 / 85 & 37 / 77 \\ \text { Never } & 12.96 \% & 10.58 \% & 15.16 \% \\ & 21 / 162 & 9 / 85 & 12 / 77\end{array}$

\section{Adverse Drug Reactions and Safety}

Table 4 presents the information concerning junior doctors' attitudes about the safety of medications. Only $33.33 \%$ physicians mentioned that side effects of drugs change their patterns of prescriptions. Alarmingly, $22.02 \%$ doctors mentioned that adverse drug reactions never affect their prescribing decisions. Regarding the counselling of patients on potential side effects of drugs, $65.92 \%$ physicians take part in effective counselling. $10.49 \%$ junior doctors mentioned that they never counsel the patients on potential side effects of prescribed drug/drugs.

Table 4 : Attitude of junior doctor towards safety

$\begin{array}{cccc}\text { Factors } & \text { All } & \text { CMOSHMC } & \text { CMCH } \\ & \mathbf{7 3 . 6 3 \%} & \mathbf{7 5 . 8 9} \% & \mathbf{7 1 . 2 9} \% \\ \mathrm{n}=162 / 220 & \mathrm{n}=\mathbf{8 5} / 112 & \mathrm{n}=\mathbf{7 7} / 108\end{array}$

How much the chance of an Adverse Drug Reaction (ADR) affects your prescribing decision?

\begin{tabular}{|c|c|c|c|}
\hline Very much & $\begin{array}{r}33.33 \% \\
54 / 162\end{array}$ & $\begin{array}{r}32.94 \% \\
27 / 85\end{array}$ & $\begin{array}{r}34.98 \% \\
27 / 77\end{array}$ \\
\hline \multicolumn{4}{|c|}{$\begin{array}{l}\text { Only when I am } \\
\text { asked by a patient }\end{array}$} \\
\hline about ADR & $50 \%$ & $51.52 \%$ & $48.72 \%$ \\
\hline \multirow{3}{*}{ Not at all } & $81 / 162$ & $44 / 85$ & $37 / 77$ \\
\hline & $22.02 \%$ & $15.52 \%$ & $16.97 \%$ \\
\hline & $27 / 162$ & $14 / 85$ & $13 / 77$ \\
\hline
\end{tabular}

To what extent you counsel the patient on potential side effects before prescribing a drug/drugs?

$\begin{array}{lrrr}\text { Always } & 38.27 \% & 40.82 \% & 36.34 \% \\ & 62 / 162 & 33 / 85 & 28 / 77 \\ \text { When feeling } & & & \\ \text { necessary } & 65.92 \% & 48.22 \% & 56.41 \% \\ & 82 / 162 & 40 / 85 & 43 / 77 \\ \text { Never } & 10.49 \% & 12.76 \% & 7.25 \% \\ & 17 / 162 & 11 / 85 & 6 / 77\end{array}$

\section{DISCUSSION}

Proper and adequate prescribing attitude is the cornerstone of modern clinical practice. Numerous factors govern the reasoning behind every prescription decision of the medicines. Some of these factors are the prescriber's and the patient's situation, professional environment, etc ${ }^{14,15}$. The present study was aims to evaluate the factors influence drug choice and the prescribing attitudes of junior doctors in two largest government and private tertiary care hospitals of Chittagong city, Bangladesh.

Junior doctors base their choices while prescribing by following their clinical teachers. For this reason, medical curriculam adopted by different universities should emphasise more on therapeutic reasoning ${ }^{16}$. Reports from various countries show that junior medical doctors do not feel prepared to prescribe independently ${ }^{17,18}$. Some surveys show that intern doctors are not even competent enough in writing a prescription ${ }^{19,20}$. Many studies revealed that junior doctors mainly copy the drug choices of the senior doctors as they lack experience. This situation 
demands that the clinical teachers should explain the reason behind every prescription to their trainee doctors ${ }^{21,22}$.

A study conducted by Riechert et al revealed that $80 \%$ physicians felt the importance of the cost of medicines while prescribing ${ }^{23}$. The similar result came out in the present study, as $79.09 \%$ percent of junior doctors took the cost of drugs seriously into consideration. A study among physicians of Greece and Cyprus (2009) found that more than $90 \%$ doctors change their prescription patterns from the fear of side effects ${ }^{24}$. However in the present study, only $33.33 \%$ junior doctors mentioned that side effects of the drug change their pattern of prescriptions. According to Rahman pharmaceutical advertisements and literature highly affect the prescribers' attitude during patient management rather than scientific literature ${ }^{25}$. In our study, only one-third $(33.95 \%)$ of the junior doctors say that pharmaceutical promotional offer never influenced them. $49.91 \%$ mentioned that they had a little influence and pharmaceutical promotions highly influence $19.13 \%$ junior doctors. Several studies revealed that the pharmaceutical sales representatives have a significant influence on drug choice ${ }^{26,27}$. Our study also shows the same result. Practice guidelines became an indispensable tool for patient management in last few decades ${ }^{28}$. However, the present study revealed that only $45.58 \%$ junior doctors' check guidelines before prescribing. The questions regarding taking a proper drug history showed that $42.59 \%$ of the junior doctors did not take proper drug history during admission/OPD consultation. This finding is similar to that of a previous survey involving healthcare professionals ${ }^{23}$.

After taking the results of the current study into consideration, it is evident that understanding the factors in uencing prescribing behavior in junior doctors is of paramount importance. There is evidence that at the early stages of a medical career, doctors may not be sufficiently competent and con dent to prescribe ${ }^{29-31}$. As prescribing errors are frequent among junior practitioners, senior doctors' proper supervision play a crucial role in this regard ${ }^{15,32}$. According to Rahman et al different studies conducted in Bangladesh revealed that prescribing behavior practiced here is irrational ${ }^{33}$. To combat this situation, the junior doctors have to have the proper training of pharmacological reasoning to improve the patient care to reduce the overall mortality and morbidity. To develop these skills among junior physicians, medical schools should implement proper education curricula on the fair therapeutic use of medicines. Over-reliance on promotional efforts and information from the pharmaceutical industries should be discouraged among junior physicians. Supervising physicians should provide the main training regarding rational prescribing attitudes. Senior doctors should follow the current standard guideline so that they can inspire the trainees under them to follow the proper evidence-based medicine approach. They should take feedback from the junior doctors on every prescription which will encourage the juniors to go through current literature more often. Hospital administrations also need to be cautious about their doctors' prescribing attitudes, and there must be well-adopted the rapeutic guidelines considering the medical, social and economic associates.

\section{CONCLUSION}

The results of the study match the findingsof other published studies regarding the prescribing attitudes adopted by the junior physicians. This study con rmed that junior doctors' prescription patterns are in uenced by multiple factors. This group of practitioners bases their choice of drug/drugs mainly by following their supervising senior doctors' prescriptions without knowing the rationale for the selection and feel less confident while prescribing. It is essential that senior doctors should clearly explain to the junior doctors how they arrived at a specific choice of medication. Issues regarding the cost of the drug, adverse drug reactions concerned the majority of physicians, but they do not have the proper training to deal with these matters. Moreover, pharmaceutical promotional offers significantly influenced junior doctors' prescribing behaviour. So, there is a need for continuous medical education programs to train the junior doctors adequately so that they develop proper therapeutic attitudes during the clinical practice.

\section{DISCLOSURE}

All the authors declared no competing interest. 


\section{REFERENCES}

1. Hogerzeil H: Promoting rational prescribing: an international perspective. Br J clin Pharmacy.1995;39:1-6

2. Richir MC, Tichelaar J, Geijteman EC, de Vries TP. Teaching clinical pharmacology and therapeutics with an emphasis on the therapeutic reasoning of undergraduate medical students. Eur J Clin Pharmacol. 2008;64(2):217-224.

3. de Vries TP. Presenting clinical pharmacology and therapeutics: A problem based approach for choosing and prescribing drugs. Br J Clin Pharmacol.1993; 35(6):581-586.

4. Denig P, Haaijer-Ruskamp FM. Therapeutic decision making of physicians. Pharm World Sci.1992;14(1):9-15.

5. Denig P. Drug choice in medical practice. Rationales, routines, and remedies. PhD Thesis, University of Groningen, Groningen. 2004

6. Han WH, Maxwell SR. Are medical students adequately trained to prescribe at the point of graduation? Views of first year foundation doctors. Scott Med J. 2006;51(4):27-32.

7. Schumock GT, Walton SM, Park HY, Nutescu EA, Blackburn JC, Finley JM, Lewis RK. Factors that influence prescribing decisions. Ann Pharmacother. 2004;38:557-562.

8. Howie JG. Clinical judgment and antibiotic use in general practice. BMJ. 1976;2:1061-1064.

9. Hartley RM, Charlton JR, Harris CM, Jarman B. Patterns of physicians use of medical recourses in ambulatory settings. Am J Public Health. 1987;77:565-567.

10. Carrin G: Drug prescribing a discussion of each variability and (ir) rationality. Health Policy. 1987; 7:73-94

11. Ryan M, Yule B, Bond C, Taylor RJ. Scottish general practitioners' attitudes and knowledge in respect of prescribing costs. BMJ. 1990;300:1316-1368

12. Bradley C. Factors which influence the decision whether or not to prescribe: the dilemma facing general practitioners. Br J Gen Pract. 1992;42:454-458.

13. Muijrers P, Grol R, Sijbrandij J, Janknegt R, Knottnerus J. Differences in prescribing between GPs. Impact of the cooperation with pharmacists and impact of visits from pharmaceutical industry representatives. Fam Pract. 2005;22:624-630.

14. Garbutt JM, DeFer TM, Highstein G, McNaughton C, Milligan P, Fraser VF. Safe prescribing: An educational intervention for medical students. Teach Learn Med. 2006;18(3):244-250.

15. Rogers E. Diffusion of innovations, 5th edn. Free Press, New York. 2003.

16. Buusman A, Andersen M, Merrild C, Elverdam B. Factors influencing GPs' choice between drugs in a therapeutic drug group. A qualitative study. Scand J Prim Health Care. 2007;25:208-213.

17. Pearson AS, Rolfe I, Smith T. Factors influencing prescribing: An intern's perspective. Med Educ. 2002; 36(8):781-787.

18. Commbes ID, Mitchell CA, Stowasser DA. Safe medication practice: Attitudes of medical students about to begin their intern year. Med Educ. 2008;42(4):427-431.

19. Lempp H, Seabrook M, Cochrane M, Rees J. The transition from medical student to doctor: Perceptions of final year students and preregistration house officers related to expected learning outcomes. Int J Clin Pract. 2005;59(3):324-329.

20. Heaton A, Webb DJ, Maxwell SR. Undergraduate preparation for prescribing: The views of 2413 UK medical students and recent graduates. Br J Clin Pharmacol. 2008;66(1):128-134.

21. Orme M, Sjoqvist F, Bircher J, Bogaert M, Dukes MN, Eichelbaum M, Gram LF, Huller H, Lunde I, Tognoni G. The teaching and organisation of clinical pharmacology in European medical schools (W.H.O. Working Group on Clinical Pharmacology). Eur J Clin Pharmacol. 1990;38(2):101-105.

22. Orme M, Reidenberg M. The teaching of clinical-pharmacology in Europe and North-America. Trends Pharmacol Sci. 1989;10(6):224-226.

23. Reichert S, Simon T, Halm E. Physicians' Attitudes about prescribing and knowledge of the costs of common medications. Archives of Internal Medicine. 2000;160:2799-2803.

24. Theodorou M, Tsiantou V, Pavlakis A, Maniadakis N, Fragoulakis V, Pavi E, Kyriopoulos J. Factors influencing prescribing behaviour of physicians in Greece and Cyprus: Results from a questionnaire based survey. 2009;9:150.

25. Rahman MS. Changes required in pharmacotherapy teaching to ensure rational use of drugs. Bang J of Physiol and Pharmacol. 1995;11:38-39.

26. Prosser H, Almond S, Walley T. Influences of GP's decision to prescribe new drugs - the importance of who says what. Fam Pract. 2003;20:61-68

27. Jones M, Greenfield S, Bradley C. Prescribing new drugs: Qualitative study of influences on consultants and general practitioners BMJ. 2001;323:1-7. 
28. US Department of Health and Human Services. Using clinical practice guidelines to evaluate quality of care, Agency for Health Care Policy and Research, Rockville, MD. 1995.

29. World Health Organization. Selection and rational use of medicines. Fact sheet No338. 2010. http://www.who.int/mediacentre/factsheets/fs338/en/

30. World Health Organization. Report of the WHO Expert Committee on national drug policies: Contribution to updating the WHO guidelines for developing national drug policies. Geneva: WHO. 1995.

31. Leape LL, Brennan TA, Laird N, Lawthers AG, Localio AR, Barnes BA et al. The nature of adverse events in hospitalized patients. Results of the Harvard Medical Practice Study II. N Engl J Med. 1991;324(6):377-384.

32. Orme M, Reidenberg M. The teaching of clinical-pharmacology in Europe and North-America. Trends Pharmacol Sci. 1989;10(6):224-226.

33. Rahman MS. Begum M. Khan I.A. Chowdhury S. Islam A.M.Z. Sultana R. Hoque M.Z. Akhter N. A Baseline Survey on the Use of Drugs at Private Practitioner Level in Bangladesh. Bangladesh Journal of Physiology and Pharmacology, 1998;14(2):47-50. 